\title{
Is Lexicography Making Progress? On Dictionary Use and Language Learners' Needs
}

Michaël Abecassis, Department of Modern Languages, University of Oxford, Oxford, United Kingdom (michael.abecassis@modern-languages.oxford.ac.uk)

\begin{abstract}
This article sets out to explore the ways native speakers as well as foreign language learners use dictionaries and the strategies dictionary users adopt in the language acquisition process. The basis for this article is a corpus of six books (in chronological order Atkins (Ed.) 1998, Nesi 2000, Tono 2001, Humblé 2001, Sin-wai (Ed.) 2004 and Thumb 2004) that look at both the usage of bilingual, monolingual and bilingualised dictionaries and the users' behaviour in the consultation process. Both the bilingual and monolingual dictionaries seem to be used independently, depending on whether the user wants to utilise them for comprehension, translation or production with regard to a foreign language. As pointed out in the literature on lexicography, some of these dictionaries, though they have undergone many changes over the years, still have serious limitations as learning tools, but the user's performance is also under investigation in empirical research, with the aim of optimising dictionary effectiveness as well as developing the language learner's skills.
\end{abstract}

Keywords: LEXICOGRAPHY, MONOLINGUAL, BILINGUAL, BILINGUALISED, DICTIONARIES, LANGUAGE ACQUISITION, DICTIONARY USER, LOOK-UP STRATEGIES, THINK-ALOUD, TRANSLATION, CORPUS, SKILLS

Opsomming: Maak leksikografie vordering? Oor woordeboekgebruik en taalaanleerders se behoeftes. Die doel van hierdie artikel is om die maniere te verken waarop beide moedertaalsprekers en vreemdetaalaanleerders woordeboeke gebruik en die strategieë wat woordeboekgebruikers toepas by die taalverwerwingsproses. Die basis vir hierdie artikel is 'n korpus van ses boeke (in chronologiese volgorde Atkins (Red.) 1998, Nesi 2000, Tono 2001, Humblé 2001, Sin-wai (Red.) 2004 en Thumb 2004) wat kyk na sowel die gebruik van tweetalige, eentalige en vertweetaligde woordeboeke as die gebruikers se gedrag by die raadplegingsproses. Beide die tweetalige en eentalige woordeboeke word skynbaar onafhanklik gebruik, afhangende daarvan of die gebruiker hulle wil aanwend vir begrip, vertaling of produksie met betrekking tot ' $n$ vreemde taal. Soos die literatuur oor leksikografie aantoon, het sommige van hierdie woordeboeke, alhoewel hulle deur die jare baie veranderinge ondergaan het, steeds ernstige beperkinge as leerwerktuie, maar die gebruiker se prestasie word ook in empiriese navorsing ondersoek met die doel om sowel die effektiwiteit van woordeboeke te verhoog as om die taalaanleerder se vaardighede te ontwikkel.

Sleutelwoorde: LEKSIKOGRAFIE, EENTALIGE, TWEETALIGE, VERTWEETALIGDE, WOORDEBOEKE, TAALVERWERWING, WOORDEBOEKGEBRUIKER, NASLAANSTRATEGIEË, HARDOP-DINK, VERTALING, KORPUS, VAARDIGHEDE 


\section{Books under review}

Although some results given in the six books under discussion may now appear outdated, their evaluation of earlier dictionary-use research and its methodologies represents a mass of information on the progress made in lexicography these past decades. The authors who contributed to the volume edited by Atkins (1998) focus more particularly on language learners' and student translators' look-up strategies. They investigate specific questions relating to the skills users should possess to gain the most from dictionaries and improvements to dictionaries to suit the users' expectations and needs. In these researches, a number of tests and linguistic exercises are included to assess whether user-oriented dictionaries meet the students' expectations and needs. Nesi (2000) presents a series of five experiments for adult English learners and the part played by dictionaries in reading comprehension. Some consultation problems and selection of wrong entries may cause serious misinterpretations. Tono (2001) is a very comprehensive book, giving an extensive review of research findings from the 1980s to the 2000s on dictionary use in reading and vocabulary acquisition. It broaches a discussion of how to evaluate users' dictionary abilities and look-up efficiency by means of skills tests. Mainly EnglishJapanese bilingual dictionaries are the focus of this research. Humblé (2001) reviews literature on dictionary use and examines different dictionaries in order to elaborate his vision of a new kind of dictionary which would maximize users' vocabulary. Sin-wai's edited collection of papers (2004) looks at the use of bilingual dictionaries for translation and new IT technology in this domain. The emphasis of Thumb's (2004) study, finally, is on English-Chinese bilingualised dictionaries and Hong-Kong students' look-up behaviour and strategies.

This very valuable sum of information about experimental methods will contribute to broaden readers' background knowledge and provide them with a basis for future research. A review of these major studies from well-known specialists in linguistics, translation and lexicology, offers an opportunity to examine users' behaviour in the lexical acquisition process of dictionary consultation, to address questions on data collection, on the strengths and weaknesses of the authors' findings, and to look ahead to the development of lexicography in the 21st century.

\section{Defining the dictionary user}

As shown by these studies, what makes the compiling of a dictionary complex and problematic is that there is not a prototypical user, but a whole variety of users, with different cultural backgrounds which may affect their abilities. All articles are subject to possible criticism as regards the sample of users targeted or the methodology used. Other external factors such as the difficulty of the task, the time allocated, the type of dictionary used, and the frequency of con- 
sultation, if not taken into account when observing subjects' behaviour, may invalidate some of the findings. However, authors are generally aware of possible fallacies in the results of their investigation.

Dictionaries can prove hard to compare as they use different approaches and target divergent groups of prospective users. Indeed, there are, among other categories, subgroups of users: English native speakers, non-native speakers of English such as Chinese or Japanese students, language learners of many different nationalities studying a foreign language, or translators (Tono 2001: 114). As there is a great diversity of potential users, the situations in which dictionaries are used are as varied. Dictionaries can be consulted in language teaching environments such as in formal circumstances in a classroom, in a professional situation for translators or in the more informal situation of a visit to a foreign country. The tendency of researchers to narrow their studies of dictionary use to the language-learning context (more easily observable in a 'controlled' experimental environment) has at times its limitations, because the needs of a subgroup of learners, but not of all potential learners are taken into consideration.

Studies of the way language learners use their dictionaries provide valuable information for both lexicographers and language teachers. They aim at improving not only the dictionaries but also the look-up abilities of their users. As Humble (2001: 21) notes, the best dictionary compiler is in fact one who is him-/herself a dictionary user and a language learner. In fact, the points of view of experienced language teachers are more unbiased and reliable than those of some lexicographers and academic researchers whose knowledge of dictionary use and language teaching can be limited. It is true that existing dictionaries tend to be made by native speakers who, judging on their intuition rather than on empirical knowledge, are less aware of the language difficulties of their mother tongue than language learners (Humblé 2001: 73). Humblé combines, as he describes himself, the expertise of a foreign language learner, a university lecturer, a researcher, and a dictionary compiler. His exposure to lexicography and language teaching is very valuable in assessing how current dictionaries fail in conveying information and how they can be improved.

The use of a dictionary has now become an indispensable component of home and academic life. Three main types of dictionaries: monolingual, bilingual and bilingualised dictionaries, and two main categories of users: native speakers and foreign language learners can be identified. It must be stressed that some cultures are more dictionary literate than others. In France, for instance, French speakers learning English have a range of monolingual dictionaries to hand, but the two most popular are perhaps Le Petit Larousse and Le Petit Robert. As the latter is more literary than the former, users will tend to utilise it for academic research and translation. Le Petit Larousse targets a wider audience, not necessarily students or academics: it is more compact and, unlike Le Petit Robert, provides numerous illustrations. Nevertheless it can be said that the choice of a dictionary is quite arbitrary, often a question of taste. Some grow up with a particular dictionary and, being familiar with its layout and conventions, tend to keep using it. 
Monolingual dictionaries of the type of Le Petit Larousse and Le Petit Robert are no longer language 'tools' for foreign learners but rather 'repositories' (Humblé 2001: 24) whose taxonomy, in the tradition of the various editions of the Dictionnaire de l'Académie, originally endeavours to preserve standard language and proscribe non-standard usage. Nesi (2000: 102) has proven that language background and culture somehow have an influence on the way a user consults a dictionary and on his/her look-up efficiency. For English-speaking societies, the proximity with English (used as a lingua franca) is certainly an asset, while for cultures whose mother tongue is remote from English, the need for contextualised English dictionaries is paramount to help them understand the cultural background with which they are unfamiliar.

In the 1970s, the traditional monolingual dictionaries gave birth to a new concept: a descriptive rather than a normative language learner's dictionary. The main disadvantage of a learner's dictionary is that by simplifying its definitions and reducing the number of entries to make it accessible to students not familiar with the language, it tends to exclude 'the least frequent words that cause most trouble to native speakers' (Humblé 2001: 35). It might also restrict it to the least proficient language learners, as advanced learners look for a more exhaustive number of entries and less frequent words in the linguistic repertoire. A study conducted by Nesi on the two editions of a learner's dictionary, COBUILD 1 and COBUILD 2, shows 'entries are getting longer, and the number of examples within each entry is increasing' (2000: 137) to suit a greater diversity of users. Although the size of some of these entries makes it denser and therefore more complex for the user, especially beginners, larger and more comprehensive dictionaries are highly rated by reviewers.

\subsection{Monolingual versus bilingual: which is the better?}

One of the difficulties dictionary users encounter in using a monolingual dictionary is the abstruse 'metalanguage of the definitions' (Thumb: 2004: 4) which they find too lengthy or difficult to decode. Sometimes, they need to look up several words contained within a definition. This inability to understand definitions leads to frustration or inhibition which prevents language acquisition and causes the avoidance of monolingual dictionaries, whatever their linguistic skills in L2 and the task to be performed (Atkins and Varantola in Atkins 1998: 38). Learners are also frequently misled and confused by multi-sense entries, ${ }^{1}$ being unable to retrieve the appropriate meaning of a word from all its possible meanings. Likewise, attempts to find information on collocations and the grammar of a particular structure often ends up in failure. Tracing an idiomatic phrase or realising that a phrase is an idiom are also problematic for many dictionary users.

Most studies conducted show that foreign language learners normally favour bilingual to monolingual dictionaries (Thumb 2004: 5), Nesi, however, adding that they generally 'use them badly' (1999: 65). Similar findings, that 
both language learners and translators favour bilingual dictionaries, emerge in Atkins (1998). For translation, the research conducted by Bogaards (see Nesi 2000: 22) states that bilingual dictionaries are more effective, although they do not favour vocabulary retention. In fact, Tomaszczyk (see Nesi 2000: 6) showed that monolingual dictionaries are more useful to foreign dictionary users who are advanced learners. They are said to improve their vocabulary and help them acquire sophistication. High proficiency learners, unlike low proficiency learners, often take to monolingual dictionaries when bilingual dictionaries do not suffice for finding extra information on a word meaning. Figures show that monolingual dictionary consultation increases with learners' linguistic maturity (Nesi 2000: 29).

When a dictionary is consulted to do a translation, figures demonstrate that bilingual dictionaries are overall more effective than monolingual dictionaries, resulting in a higher success rate (Atkins and Varantola in Atkins 1998: 99). The most effective translations are produced by those who consulted a dictionary prior to translating. Those translating into their own language appear to be more satisfied with their translation because of their familiarity with the language, but this does not necessarily imply a successful translation. Trained translators in their search for perfection do not use one but several dictionaries. They consult a variety of sources (a whole range of reference books and text bases) to corroborate their results.

Advanced English learners use dictionaries more than elementary learners (Thumb 2004: 11). At an early stage of their language training, foreign language students have limited communication skills and vocabulary abilities. They are confronted with simpler messages which do necessitate the frequent use of a dictionary. At this level, the dictionary needs to display clear and learnerfriendly examples. As they become more proficient and tend to native-like fluency, learners wish, on the one hand, to make use of a more elaborate lexis with the use of metaphors, culture-specific idioms and correct collocations and, on the other hand, to develop knowledge of styles and 'intellectualise' (Castro in Sin-wai 2004) the culture of the target language.

Can the profile of the successful dictionary user be established? It is obviously something of a myth to believe that there will be an 'ideal' user in the same way that the concept of a 'perfect' dictionary is purely ideological. However, Thumb (2004: 105) provides some answers. The user should already have a high level of language proficiency, use both L1 (mother tongue) and L2 (foreign language) sections of the dictionary and be familiar with dictionary conventions. In other words, practice certainly makes the user, if not perfect, at least better skilled.

\subsection{Bilingualised dictionaries}

Bilingualised dictionaries bring the synergy of two dictionaries in one with exposure to L2. They are hybrids of the monolingual and bilingual dictionary. 
In a bilingualised dictionary, each headword entry is followed by a definition in L2 and an L1 translation. Studies show that users of a bilingualised dictionary have a low failure rate in word retrieval (Laufer and Hadar 1997: 192). The translation sought in such a dictionary has a reassuring effect, for the nonnative user finds confirmation for his/her understanding of the meaning of the target word and for making the right decision. Dídac et al. (2006) argue, however, that in print bilingualised dictionaries, the user does not necessarily have exposure to L2, as some pass over the monolingual L2 part and read only the L1 translation, losing the potential offered by the definition. Newly released electronic bilingualised dictionaries offer great promise for the future. Some display the monolingual L2 text and defer the L1 translation so that users do not encounter it immediately. Others, such as the Ultralingua Dictionary, separate both definition and translation with several hyperlinks, which enable users to choose their language and encourage them to consult both monolingual and bilingual sections. Another disadvantage of the print bilingualised dictionary is that it provides solely an L2 + L1 section but not the reverse. Deferred bilingualised dictionaries keep every section separated, but at the same time interrelated by means of interactive menus.

\section{Users' and dictionary strategies}

Users' lack of knowledge of dictionary conventions is often regarded as one of the main causes for their look-up failures. Lexicographical researches have been conducted with the aim of improving the dictionary as well as improving the look-up abilities of the users. By studying the way users consult their dictionaries, researchers can identify strategies, those that fail and those that assist users in being more efficient in their search. As Nesi (2000: 11) points out, questionnaires to evaluate users' strategies, speed and performance in dictionary consultation have been subject to controversy. Indeed, it is rather difficult to measure whether the respondents' answers are actually a reflection of what they do or think or whether they are putting forward a positive view of their abilities, embellishing what they actually do and think. Research based on observation of dictionary users' behaviour can prove holistic in a contrived experimental situation. The size of the group to be investigated can also be a major disadvantage. A group of less than 20 participants does not seem enough to constitute a representative sample, but the larger the number, the more difficult it is to monitor.

It is necessary to be aware of users' different motivations for consulting a dictionary when evaluating the best possible strategies for successful look-ups. A linguistic activity of some sort such as speaking, reading and translating is what triggers the use of a dictionary. Tarp (in Sin-wai 2004: 28) contrasts two types of situations where the user will consult a dictionary: 'communicationorientated' and 'knowledge-orientated' situations. Generally users' look-ups for new words in a dictionary are in decreasing order of preference for meaning, 
pronunciation and spelling. Proficient users would look most specifically for typical collocations and idioms.

The less proficient in English an EFL student is the more he/she will need to resort to dictionaries in order to broaden his/her vocabulary. With language proficiency he/she also acquires a better judgement on when to consult a dictionary. His/her failure in using dictionaries might be due to a lack of expertise in dictionary use, as researchers generally notice. It has been found that $80 \%$ of the French speakers investigated for the EURALEX/AILA Research Project had no expertise in the use of a dictionary (Atkins and Varantola in Atkins 1998) ${ }^{2}$. The foreign language learner's lack of dictionary-using skills has been widely observed (Nesi 1999), testifying to the little importance given to dictionary training in language teaching. Language users also often ignore the wealth of information that the dictionary contains and make little use of the extra features its microstructure has to offer (Tono 2001: 114). In addition, learners have problems in becoming sensitised to the register of words they are using. They may use colloquial vocabulary in formal situations and rather stilted vocabulary in casual contexts. In dictionaries, vocabulary is stylistically labelled to indicate technicality or level of informality.

Studies have been conducted to establish whether definitions or examples or both in dictionary entries contribute to a better understanding of the target word. Findings unsurprisingly tend to show that for comprehension 'new words were best learned when they were both defined and illustrated' (Tono 2001: 23). Examples are used to corroborate dictionary definitions and, by conveying linguistic information, they certainly enhance the learning process but it still needs to be determined whether this helps vocabulary retention. The question of whether authentic examples are more beneficial to language use than made-up ones is the source of some debate (Humblé 2001: 78, Nesi 2000). In the 1980s, corpus-based dictionaries started including examples from newspaper articles, and speeches recorded in naturally-occurring situations ${ }^{3}$. This concept of authenticity is, as Humblé points out, purely arbitrary: 'the fact that a native speaker produced an utterance does not render it authentic' (2001: 78). Madeup examples are, on the contrary, grammatically correct but not genuine, for the lexicographer would tend to combine several grammatical problems in one. The hackneyed example given for a long time in English grammars of French as illustrative of the possessive case, 'la plume de ma tante', sounds rather artificial out of context, and it is very unlikely a user will come across such an example in real life. Made-up examples have the benefit of illustrating a particular grammatical point or even combining difficulties, but there is no doubt that the use of authentic material has a psychological impact on users who feel they are exposed to the language as it is used.

To collect data on users' look-up strategies, think-aloud is widely accepted to be an effective tool (Thumb 2004: 33) for evaluating the thinking process of a dictionary user during consultation. The process of dictionary consultation implies 'a series of deliberate, metacognitive and cognitive steps learners take in 
acquiring and retrieving dictionary information' (Thumb 2004: 85). It has been used in fields such as psychology and science to assess knowledge acquisition. Thumb has studied the look-up strategies of a sample of advanced learners of English in Hong Kong while consulting a bilingualised English-Chinese learner's dictionary. It has been argued that some look-up strategies will enable the user to be successful in retrieving the appropriate word, while others will be misleading (Thumb 2004: 32). Her analysis of think-aloud data has enabled her to identify seven different dictionary-use strategies 4 :

- The ignoring strategy: The subject looking up both monosemous and polysemous words does not make use of the full ancillary information (such as the grammatical constraints, word class, etymology, etc.) available in an entry.

- The assuming strategy: The subject looking up monosemous words uses ancillary information, but assumes that the meaning in an entry is appropriate and does not apply it to the context in which it is used.

- The minimizing strategy: The subject looking up polysemous words minimises the use of definitional and ancillary information when searching for a word by reading just the first or first few senses of a word.

- The checking strategy: The subject infers the possible meaning of a word by checking if it matches with the dictionary definition.

- The paraphrasing strategy: The subject just rewords the chosen definition of a word.

- The stretching strategy: The subject infers a context-fitting meaning for the target word common to all definitions in an entry.

- The maximising strategy: The subject scans all the meanings of the target word in an entry to reduce it to one.

Thumb's results indicate that both higher and lower proficiency subjects used the L1 as frequently as the L2 part of bilingualised dictionaries, but would prefer L1 for some words and L2 for others (Thumb 2004: 98). Using different lookup strategies does not guarantee success, but learners using the assuming and checking strategies proved on the whole more successful in retrieving the correct meaning of a target word.

\section{Dictionaries and translation}

The translation activity and users' strategies have been the focus of Thumb's analysis (2004) in the context of Hong Kong students using a bilingualised dictionary for reading comprehension. Sin-wai's book (2004), most particularly focusing on Chinese/English translation, gives a complementary survey of the progress made by lexicography in the field of translation. This is a topic on 
which little research has been conducted. The book brings together experts in translation studies and translation practice and lexicographers, mostly of Chinese origin. Not only do they look at new trends in dictionary compilation, but they also discuss the translation friendliness of monolingual, bilingual and ultimately bilingualised dictionaries. The bilingual dictionary is often inadequate, unless words are organised and cross-referenced, in the same way as in thesauri, according to semantic domain templates, as suggested by Moe (in Sinwai 2004: 55-62). Indexed words can thus be compared and contrasted, making it easier for the user to find an equivalent in the entire lexicon. The development of new technologies for the translation market (bilingual corpora, computer translation software and machine translation) has provided quickly and easily updated resources. Translation memory enables the storage of a database of previously translated sentences which could be provided to the user at any time (Yihua in Sin-wai 2004: 104). In our globalized world with English expanding in China, Kam-mei and McArthur (in Sin-wai 2004: 126) imagine that tomorrow's dictionary for the Hong Kong population will be biliterate and trilingual in accordance with the language policy promoted by the government. Other issues at stake in the book are the translation of metaphors and other culture-bound references. No doubt, as Yanchun and Jianhua (in Sin-wai 2004: 177-185) make it clear, translation is somewhat of a 'paradox'. Translation cannot just be a mechanical word-to-word translation, as no complete equivalents exist in two different languages. Words differ on account of their connotations and denotations. In the process of translation, something is inevitably lost and the translation of the source language will often need to compensate. In the next decade, with the improvement of electronic dictionaries, major advances can be expected in their application to translation.

\section{Producing the dictionary of the future}

Most books discussed in this article make observations in their concluding chapters on future trends in lexicography, speculating on what the dictionaries of tomorrow will look like. Nesi (2000) notes that print dictionaries are growing in size with the risk of overloading the users with too much information. As a bigger dictionary is not easy to carry around and the information is more difficult to retrieve, the solution advocated is to become electronic. Print dictionaries are constrained by space, while electronic dictionaries have no size limitations. The dictionary of the future, as seen by Rogers and Ahmad (in Atkins 1998: 193), will enable users 'to draw on electronically-stored data-bases of terms with semantically-relevant navigational paths [and] will support them in creating their own data-base'. Humblé (2001: 97) substantiates the claim that the ideal dictionary should be electronic, stressing the need to combine in a dictionary the tools for decoding with the largest number of lexical items and for encoding with the most detailed guidance on usage, syntactic features and collocates: 'A Spanish-English dictionary is supposed to help Spanish speakers 
with the understanding and production of English while at the same time assisting English speakers with the understanding and production of Spanish' (Humblé 2001: 84).

With no space constraints, the electronic dictionary ${ }^{5}$ can give access to a diversity of sources from the World Wide Web with cross-referenced links to synonyms, antonyms and thesauri. It can be multifunctional, including as much information as possible on meaning, etymology, grammar and collocations. Other multimedia applications include the use of sound-like spellings, attractive animation and visual elements such as photographs and video clips which, on account of their game-like approach, favour vocabulary acquisition. These appeal to users who find access to information not only interactive and enjoyable, but also much faster than consulting a print dictionary. With a concordancer and software such as WordSmith and Multiconcord, students also have the possibility to compile their own 'virtual corpus' (Varantola in Atkins 1998: 190). These corpus data allow the study of vocabulary and collocations, particularly syntactic and lexical units, in texts extracted from Internet sources. Corpora also provide a wealth of immediately accessible examples with which no paper dictionary can compete.

\section{Conclusion}

The research conducted in the books under review is sometimes inconclusive and the statistical validity of the samples and the findings can be debated. They raise many questions, not always enlightening the reader on how to answer them. The process of dictionary consultation showing the strategies of users is a very complex phenomenon to observe. Tono (2001: 84) remarks with scepticism that 'not a single reliable measurement of dictionary using skills has become available so far'. Results to record subjects' behaviour are often difficult to interpret and seem artificial in a non-natural environment. It would be advisable, as he (Tono 2001: 36) suggests, to have them verified 'in a more natural classroom setting' or in real-life social situations, both formal and informal. Other findings prove statistically to be rather obvious or common-sense (the use of a dictionary affects the amount of time spent to complete a test), but they open lines of investigation on how to improve both the users' skills and the general design of the dictionary. Future researchers learning from their predecessors will certainly be guided to prevent the same pitfalls. For an improved bilingual dictionary, researchers of both L1 and L2 are now expected to collaborate. In the 1930s, Ščerba had already imagined a reference tool to assist users in decoding and encoding, combining four dictionaries in one and providing translation $\mathrm{A} \rightarrow \mathrm{B}$ and $\mathrm{B} \rightarrow \mathrm{A}$ for users with the mother tongue $\mathrm{A}$ and $A \rightarrow B$ and $B \rightarrow A$ for users with the mother tongue B' (Berkov 1996, quoted by Humble 2001: 98). This is hardly conceivable in paper-based form. However, in the near future, electronic dictionaries or CD-ROM versions will be seen becoming multifunctional, combining in one programme the potential of the 
monolingual, bilingual and bilingualised dictionaries. CD-ROMs now provide users with instructions and a virtual guided tour of their dictionary potential, ensuring participants some form of training in dictionary skills they usually lack.

Tono (2001: 216-217) is confident that new IT technology, which creates 'a user-friendly learning environment' will have some influence on subjects' behaviour and will improve their dictionary skills, by giving them access, in the most interactive way, to large lexical databases. Facing the computer, students do not experience the inhibitive fear and panic which are often prevalent in the classroom situation. Despite general enthusiasm towards on-line computer-based dictionaries and CD-ROMs, however, little research has been conducted on their efficiency. At this stage, it is hard to assess whether fast searches in an electronic dictionary actually improves vocabulary acquisition and permits retention, but the electronic dictionary of the third millennium holds many promises for better skilled and more proficient foreign language speakers.

\section{Notes}

1. A single entry can contain polysemous meanings ranging from general to more technical fields. OALECD for instance gives four main senses for the word 'blade' (Thumb 2004: 96).

2. Pupils in France are normally taught to use a dictionary as early as primary school: at an early age (in CE1), children's picture dictionaries and then gradually (from CM1 onwards), Le Petit Larousse.

3. Moon (1989) argues that the selection of texts used to compile corpus-based dictionaries are ideologically 'dominated by published texts written by middle-class writers for a middleclass readership' (quoted by Benson in Sin-wai 2004: 46).

4. Nesi (2000: 91) suggests, moreover, that confusion with 'some phonologically and orthographically similar word' is a major cause of error.

5. Electronic dictionaries fall into three categories: 'hand held devices, dictionaries on disk and CD-ROM, and dictionary Websites' (Nesi 2000: 142).

\section{References}

Atkins, B.T. Sue (Ed.). 1998. Using Dictionaries: Studies of Dictionary Use by Language Learners and Translators. Lexicographica. Series Maior 88. Tübingen: Max Niemeyer.

Berkov, Valerij. 1996. Passive vs. Active Dictionary. A Revision. Euralex '96 Proceedings. Papers Submitted to the Seventh EURALEX International Congress on Lexicography in Göteborg, Sweden: 547-550. Göteborg: Göteborg University, Department of Swedish.

Bogaards, Paul. 2001. Dictionnaire pédagogiques et apprentissage du vocabulaire. Cahiers de Lexicologie 59: 93-107.

COBUILD 1: Sinclair, John M. (Ed.). 1987. Collins COBUILD English Dictionary. London/Glasgow: Collins. 
COBUILD 2: Sinclair, John M. (Ed.). 1995. Collins COBUILD English Dictionary. London: HarperCollins.

Dídac, Pujol, Corrius Montse and Joan Masnou. 2006. Print Deferred Bilingualised Dictionaries and Their Implications for Effective Language Learning: A New Approach to Pedagogical Lexicography. International Journal of Lexicography 19(2): 197-215.

Humblé, Philippe. 2001. Dictionaries and Language Learners. Frankfurt: Haag und Herchen.

Laufer, Batia and L. Hadar. 1997. Assessing the Effectiveness of Monolingual, Bilingual, and 'Bilingualised' Dictionaries in the Comprehension and Production of New Words. The Modern Language Journal 81(2): 189-196.

Moon, Rosamund. 1989. Objective or Objectionable? Ideological Aspects of Dictionaries. English Language Research 3: 59-94.

Nesi, Hilary. 1999. The Specification of Dictionary Reference Skills in Higher Education. Hartmann, R.R.K. (Ed.). Dictionaries in Language Learning. Recommendations, National Reports and Thematic Reports from the TNP Sub-Project 9: Dictionaries: 53-66. Berlin: Free University Berlin.

Nesi, Hilary. 2000. The Use and Abuse of Learners' Dictionaries. Lexicographica. Series Maior 98. Tübingen: Max Niemeyer.

OALECD: Hornby, A.S. and P.T. Lee (Eds.). 1994. Oxford Advanced Learner's English-Chinese Dictionary. Hong Kong: Oxford University Press.

Sin-wai, Chan (Ed.). 2004. Translation and Bilingual Dictionaries. Tübingen: Max Niemeyer.

Thumb, Jenny. 2004. Dictionary Look-up Strategies and the Bilingualised Learner's Dictionary: A ThinkAloud Study. Tübingen: Max Niemeyer.

Tomaszczyk, I. 1979. Dictionaries: Users and Uses. Glottodidactica 12: 103-119.

Tono, Yukio. 2001. Research on Dictionary Use in the Context of Foreign Language Learning. Tübingen: Max Niemeyer.

Ultralingua Dictionary. http://www.ultralingua.net. 